\title{
ANÁLISE DAS MARCAS DE SUBJETIVIDADE NO TEXTO DE GÊNERO NOTÍCIA SOB UM OLHAR ENUNCIATIVO
}

\section{ANALYSIS OF SUBJECTIVITY MARKS IN THE NEWS GENRE TEXT UNDER AN ENUNCIATIVE PERPECTIVE}

\author{
Claudia Toldo ${ }^{1}$
}

Estela Mettler Piva ${ }^{2}$

\begin{abstract}
RESUMO: Este trabalho se insere na linha de pesquisa da Teoria da Enunciação, idealizada na linguística enunciativa de Émile Benveniste. Trabalhamos, especialmente, com o texto $D a$ subjetividade na linguagem (1958), de Benveniste, que nos apresenta o conceito de subjetividade na linguagem e suas marcas no discurso. Observando esse conceito principal, o objetivo deste trabalho é analisar enunciativamente o advérbio na construção do sentido do texto do gênero notícia, mostrando que essas escolhas são marcas que desvelam uma subjetividade de sujeitos que se enunciam em textos. O corpus deste trabalho é um texto do gênero notícia selecionado de um jornal de circulação nacional, a fim de observar, analisar e descrever o emprego das formas - advérbios - em função da construção dos seus sentidos.
\end{abstract}

PALAVRAS-CHAVE: Linguística da Enunciação. Subjetividade. Notícia. Advérbios.

ABSTRACT: This work is in line with the Theory of Enunciation, idealized in Émile Benveniste's Linguistics of Enunciation. We work especially with the text Subjectivity in Language (1958), by Benveniste, which introduces us to the concept of subjectivity in language and its marks in discourse. Observing this main concept, the objective of this work is to enunciatively analyze the adverb in the meaning construction of the text of the news genre, showing that these choices are marks that unveil the subjectivity of subjects who enunciate themselves in texts. The corpus of this work is a text of the news genre selected from a newspaper with national circulation, in order to observe, analyze and describe the employ of the forms - adverbs - in the function of the construction of the meanings.

KEYWORDS: Linguistics of Enunciation. Subjectivity. News. Adverbs.

\footnotetext{
${ }^{1}$ Doutor em Letras. Professora de Língua Portuguesa e Linguística do curso de Letras da Universidade de Passo Fundo; Professora e Coordenadora do PPGL - Doutorado e Mestrado em Letras na mesma Universidade; realiza pesquisas em Teorias da Enunciação, principalmente, estuda as reflexões teóricas de Émile Benveniste; pesquisadora CNPq; claudiast @upf.br

${ }^{2}$ Graduada em Letras - Português/Inglês pela Universidade de Passo Fundo (UPF/RS). Foi bolsista PIBIC e atualmente é pesquisadora voluntária na linha de pesquisa "Constituição e interpretação do texto e do discurso", com orientação da professora Claudia Toldo; pivaestela@gmail.com
} 


\section{PERcursos Linguísticos • Vitória (ES) •v. 11 •n. 29 • 2021 • ISSN: 2236-2592 • Dossiê temático $\bullet O$ texto na pesquisa e no ensino: conhecimentos, práticas e desafios na contemporaneidade •}

\section{Considerações iniciais}

Ouvimos nas conversas do nosso dia a dia que "notícia boa deve ser imparcial", "um texto jornalístico é neutro, não pode demonstrar a opinião do jornalista que o escreveu" e assim por diante. Mas será que existe essa neutralidade nos textos que nós, locutores, independentemente da profissão, escrevemos? Essas e outras questões são o ponto de partida para a construção deste trabalho: quais são as marcas que o locutor deixa no texto que escreve? Como este locutor "se marca" no texto? Essas marcas são identificáveis mesmo em textos que, teoricamente, são objetivos?

Buscamos, nos estudos do linguista da Enunciação, Émile Benveniste, as respostas que queremos com esses questionamentos. Através do estudo do texto Da subjetividade na linguagem (1958), pretendemos entender melhor a neutralidade (ou não) nos textos e as marcas subjetivas deixadas pelo locutor.

Para exemplificar a teoria, escolhemos e analisamos um texto jornalístico de gênero notícia, colocando em foco o conceito de subjetividade. Nosso trabalho, portanto, é de cunho teórico-analítico: analisamos, a partir de uma reflexão teórica, a construção de sentido de determinadas formas linguísticas empregadas em um texto, enquanto corpus de análise. Nosso objetivo é observar o sentido construído pelos advérbios na notícia e mostrar que essas escolhas são marcas que desvelam uma subjetividade mesmo em textos que, teoricamente, são objetivos.

Passemos então, primeiramente, às considerações feitas por Émile Benveniste quanto à subjetividade na linguagem.

\section{A subjetividade da linguagem: uma marca explícita?}

Primamos pelo texto $D a$ subjetividade na linguagem, pois é nele que encontramos respostas para nossos questionamentos iniciais. É nesse texto de 1958, publicado no Journal de psychologie, que Benveniste nos explica seu olhar sob a subjetividade e o que, afinal, é ela. Também é nesse texto que reconhecemos quais são as marcas de subjetividade deixadas em um texto e como identificá-las, possibilitando-nos um deslocamento teórico-analítico. A palavra "subjetividade" nos faz pensar em vários significados e nos faz atribuir vários sentidos em diferentes situações; não seria diferente, portanto, o seu uso no texto de Émile Benveniste, que publica essa reflexão em um periódico da área de Psicologia, fato que prova a grandiosidade do 


\title{
PERcursos Linguísticos • Vitória (ES) •v. 11 •n. 29 • 2021 • ISSN: 2236-2592 • Dossiê temático $\bullet O$ texto na pesquisa e no ensino: conhecimentos, práticas e desafios na contemporaneidade •
}

tema e a intertextualidade da Linguística com outras áreas, especialmente, aqui, com a Psicologia.

Benveniste (2005, p. 284) inicia seu texto questionando: se "a linguagem é [...] um instrumento de comunicação, a que deve a ela essa propriedade?" Afirma que, por isso, sua função primeira é a de comunicar, de se fazer entender a outros indivíduos. Porém, logo em seguida, o linguista nos provoca a pensar sobre o uso da palavra "instrumento"; afinal, a linguagem é inerente ao ser humano e não foi criada ou inventada por ele. Nas palavras de Benveniste (2005, p. 285):

\begin{abstract}
Na realidade, a comparação da linguagem com um instrumento, e é preciso realmente que seja com um instrumento material para que a comparação seja pelo menos inteligível, deve encher-nos de desconfiança, como toda noção simplista a respeito da linguagem. Falar de instrumento, é pôr em oposição o homem e a natureza. A picareta, a flecha, a roda não estão na natureza. São fabricações. A linguagem está na natureza do homem, que não a fabricou.
\end{abstract}

Ou seja, nós só encontramos a linguagem no discurso dos falantes, uma vez que a língua só é língua quando enunciada. Por enunciação, trata-se da atividade de "colocar em funcionamento a língua por um ato individual de utilização" (BENVENISTE, 2006, p. 82). Em outras palavras, a enunciação é o ato de colocar a língua em ação, é a língua em sua função primeira: a de comunicar. Dessa forma, não podemos dizer que a linguagem é algo acessório ou que é um instrumento, pois ela faz parte da natureza dos seres humanos. Ao contrário dos instrumentos, que foram inventados, criados ou gerados pelos homens, a língua é inerente ao ser humano: nascemos com essa capacidade de nos comunicar e, por isso, somos seres sociáveis e distintos das outras espécies vivas justamente por termos essa faculdade da linguagem.

Se o homem se comunica com outros homens através da linguagem, é dessa forma e, somente dessa forma, que ele se constitui como sujeito. Somente depois de esclarecer essa relação entre homem e linguagem é que Benveniste nos diz que essa capacidade do locutor de se colocar como sujeito é o que chamamos de subjetividade. A subjetividade, por sua vez, é a maneira pela qual nós, falantes, nos expressamos. Benveniste (2005, p. 286) explica que: "eu não emprego $e u$ a não ser dirigindo-me a alguém, que será na minha alocução um $t u$ ”. Ou seja, nós falamos com outros falantes. Nós, enquanto locutores, propomo-nos como sujeito de nosso dizer à medida que instituímos o outro - enquanto "tu" - como nosso alocutário. É nesse exercício da língua e com a língua que encontramos o fundamento da subjetividade.

Percebemos que a subjetividade é um fator de extrema importância para que haja linguagem, para que a comunicação entre os homens seja possível. Toda vez que eu falo, 


\section{PERcursos Linguísticos • Vitória (ES) •v. 11 •n. 29 • 2021 • ISSN: 2236-2592 • Dossiê temático $\bullet O$ texto na pesquisa e no ensino: conhecimentos, práticas e desafios na contemporaneidade •}

coloco-me no lugar de $e u$ e esse lugar de $e u$ suscita, mesmo que inconscientemente, um $t u$, um interlocutor. É com esse contraste entre $e u$ e $t u$ que a linguagem acontece e que os sujeitos se comunicam.

De fato, a linguagem corresponde a isso em todas as suas partes. É tão profundamente marcada pela expressão da subjetividade que nós nos perguntamos se, construída de outro modo, poderia ainda funcionar e chamar-se linguagem. (BENVENISTE, 2005, p. 287).

Todas as línguas possuem os pronomes pessoais e são com eles que nos expressamos. Porém, “não há conceito de 'eu' englobando todos os $e u$ que se enunciam a todo instante na boca dos falantes" (BENVENISTE, 2005, p. 288), ou seja, não há e não teria como haver um conceito de eu para cada uso individual, e assim acontece com todos os signos da língua. Toda vez que nos apropriamos desse "tesouro virtual depositado no cérebro de cada falante" (CLG, 2012, p. 45), conforme Saussure, para colocar a língua em uso, temos uma nova enunciação. Então, toda vez que falamos "bom dia", falamos de um novo bom dia, de um novo ato enunciativo.

Se o $e u$ pode, então, se referir a um uso em particular e também é usado para se referir a todos os indivíduos em todos os seus usos de forma geral, o que é, afinal, o eu? Benveniste (2005, p. 288) nos responde: " $e u$ se refere ao ato de discurso individual no qual é pronunciado, e lhe designa o locutor." Estamos, portanto, diante de um termo que só é identificado e só faz sentido em seu uso atual, na língua em uso:

\footnotetext{
A realidade à qual ele remete é a realidade do discurso. É na instância de discurso na qual $e u$ designa o locutor que este se enuncia como "sujeito". É portanto verdade ao pé da letra que o fundamento da subjetividade está no exercício da língua. (BENVENISTE, 2005, p. 288).
}

Os pronomes pessoais, portanto, são alguns dos termos que sustentam a subjetividade da linguagem, que, por sua vez, está organizada de forma que "permite a cada locutor apropriarse da língua toda designando-se com eu." (BENVENISTE, 2005, p. 288). Dessa forma, o uso dos pronomes pessoais é uma (e talvez a primeira) marca que deixamos em nossos textos, juntamente com as flexões de verbos, adjetivos, advérbios, outros pronomes e outros termos que revelam a identidade de um texto ou mostram que determinado texto não é totalmente objetivo, como mostraremos, mais adiante, na análise.

Outra marca muito importante para desvelarmos a subjetividade de um texto se refere à sua temporalidade. Sabemos que as línguas, em geral, possuem tempos verbais passado, 


\title{
PERcursos Linguísticos • Vitória (ES) •v. 11 •n. 29 • 2021 • ISSN: 2236-2592 • Dossiê temático $\bullet O$ texto na pesquisa e no ensino: conhecimentos, práticas e desafios na contemporaneidade •
}

presente e futuro, porém sempre usamos como referência temporal o agora, o tempo presente, já que é nesse momento que o acontecimento de um fato e sua narração coincidem. Não poderia, então, ser diferente:

\begin{abstract}
Não há outro critério nem outra expressão para indicar o "tempo em que se estâ" senão tomá-lo como "o tempo que que se fala". Esse é o momento eternamente "presente", embora não se refira jamais aos mesmos acontecimentos de uma cronologia "objetiva" porque é determinado cada vez pelo locutor para cada uma das instâncias de discurso referidas. (BENVENISTE, 2005, p. 289, grifos do autor).
\end{abstract}

Assim dizendo, "a temporalidade humana com todo o seu aparato linguístico revela a subjetividade inerente ao próprio exercício da linguagem" (BENVENISTE, 2005, p. 289). A linguagem contém todas as formas linguísticas adequadas a cada momento e a cada tempo. Essas formas são apropriadas por cada falante na enunciação e, quando a linguagem é posta em discurso, há a possibilidade da subjetividade.

Cada vez que o falante se apropria da língua, ele se refere à sua pessoa, utilizando o eu e incitando um $t u$. Dessa forma e por esse motivo, o eu é uma nova enunciação toda vez em que é usado pelos falantes de uma língua. Assim é constituída a instância do discurso e a categoria de pessoa ("eu" e "tu"): a subjetividade instalada na linguagem. Destacamos que a "subjetividade" tratada neste trabalho diz respeito à capacidade de o locutor se propor como “sujeito". Como diz Benveniste (2005, p. 286): "É 'ego' que diz ego".

Assim, apoiamo-nos nas palavras de Flores (2013): “O homem é homem porque tem linguagem. Opor o homem à linguagem é opô-lo à sua própria natureza". Isso é evidenciado em Benveniste, uma vez que não podemos pensar o homem afastado de sua natureza subjetiva e intersubjetiva, porque é ele constituído pela linguagem. É dessa subjetividade que tratamos aqui.

Para analisarmos como o locutor se marca nos textos que escreve, escolhemos um gênero normalmente tido como objetivo e imparcial: a notícia; e uma marca que nos aponta a escolha do locutor: o advérbio. Passemos, agora, para um breve estudo desse tipo de texto.

\section{A notícia: um texto objetivo?}

Esta seção destina-se a uma reflexão acerca do gênero textual notícia, tomando-o como um texto "objetivo", considerando sua natureza informativa e questionando essa perspectiva do ponto de vista enunciativo.

Gênero textual jornalístico mais conhecido entre a população em geral, a notícia está presente em nosso dia a dia na televisão, no rádio, no jornal impresso, em revistas, nas redes 


\section{PERcursos Linguísticos • Vitória (ES) •v. 11 •n. 29 • 2021 • ISSN: 2236-2592 • Dossiê temático $\bullet O$ texto na pesquisa e no ensino: conhecimentos, práticas e desafios na contemporaneidade •}

sociais e em sites específicos. Trata-se de um gênero não literário de caráter informativo. Seu principal objetivo, portanto, é informar sobre algum acontecimento ocorrido na vida das pessoas que vivem em sociedade. Uma notícia é "normalmente reconhecida como algum dado ou evento socialmente relevante que merece publicação numa mídia" (BENASSI, 2013, p. 1793). As notícias apresentam textos descritivos e/ou narrativos, dando as principais informações sobre o tempo, o espaço e os "personagens” envolvidos.

Eis algumas características desse tipo de texto: os textos são, geralmente, curtos, pois são objetivos e pretendem resumir um fato; a linguagem utilizada é formal e clara, pois o objetivo é fazer com que o leitor entenda as informações rapidamente; os textos apresentam título e subtítulo; o autor, no caso, o jornalista, escreve sempre em terceira pessoa; por fim, o discurso é indireto, ou seja, é o locutor quem conta a história, quem "fala" no lugar dos personagens envolvidos.

A notícia conta fatos recentes e cotidianos, já que, como o próprio nome diz, noticia um fato. A estrutura desse texto é a seguinte: título principal; título auxiliar (subtítulo); lide, que é um parágrafo inicial onde as principais perguntas são respondidas (O quê? Como? Quem? Onde? Quando? Por quê?); corpo da notícia, onde as informações são mais detalhadas. A notícia também apresenta a data de publicação e edição, que é de extrema importância, segundo Benassi (2013, p. 1794), pois "não basta que uma notícia seja verdadeira; é necessário que ela pareça verdadeira. $\mathrm{O}$ relato de fatos numa notícia deve apresentar uma data precisa e a determinação do lugar onde ele ocorreu"; essa informação pode estar logo abaixo do subtítulo ou no final do corpo do texto.

Mas se o gênero notícia é assim tão imparcial e objetivo, será que o locutor se marca, de alguma forma no texto? Se sim, como isso acontece? Passemos agora à análise de uma notícia escolhida pelas autoras.

\section{Uma possibilidade de análise}

Neste momento, propomos uma breve e inconclusa análise de um texto, apontando algumas marcas que podem nos ajudar a olhar um texto tido como notícia e realizar algumas considerações sobre a subjetividade, deslocando a reflexão teórica para uma possível análise textual. O texto foi retirado do portal de notícias de Rede Globo de televisão, G1.com, e se 


\title{
PERcursos Linguísticos • Vitória (ES) •v. 11 •n. 29 • 2021 • ISSN: 2236-2592 • Dossiê temático $\bullet O$ texto na pesquisa e no ensino: conhecimentos, práticas e desafios na contemporaneidade •
}

intitula: "Dia do fogo completa um ano com apenas 5\% dos responsáveis punidos, aponta Greenpeace ${ }^{3 "}$ (Anexo A).

Esse texto consiste em uma notícia sobre o dia do fogo, um evento organizado por fazendeiros da região do Pará para queimar terras. Segundo o site da ONG GreenPeace (2020):

\begin{abstract}
Durante os dias 10 e 11 de agosto de 2019, aconteceu no Pará o que ficou conhecido como "Dia do Fogo", quando produtores rurais da região se mobilizaram para atear fogo na Amazônia. Apenas nesses dois dias, o Instituto Nacional de Pesquisas Espaciais (INPE) detectou 1.457 focos de calor no estado, um aumento de $1.923 \%$ no mesmo intervalo, quando comparado ao ano anterior. Enquanto no dia 9 de agosto foram detectados 101 focos na região, no dia 10 esse número pulou para 715 , um aumento de $707 \%$ de um dia para o outro.
\end{abstract}

Separamos seis trechos do texto que consideramos interessantes e, em seguida, analisamos esses excertos semanticamente para refletir sobre a objetividade ou subjetividade apresentada em cada um. Portanto, essa parte se organiza da seguinte forma: excerto do texto, análise, próximo excerto, análise; e assim sucessivamente.

Pretendemos mostrar algumas marcas da construção de sentido observadas no uso dos advérbios. É sábio que o advérbio acrescenta ou modifica o sentido de uma frase. Além disso, trata-se de um termo acessório, de acordo com a Gramática Tradicional. Assim diz Rocha Lima, em sua Gramática Normativa da Língua Portuguesa, referindo-se a frases com uso de advérbios: "A força emocional dessas frases pode ser tão poderosa, que se chegue a dispensar a presença de qualquer adjetivo" (LIMA, 2018, p. 227). Tendo isso em vista, a escolha de usar o advérbio ou não e de, se usar, qual advérbio escolher para aumentar, modificar ou acrescentar sentido à frase é do autor, é de quem está escrevendo o texto. Acreditamos que é nesse ponto que o locutor "se marca" no texto: nesta escolha pessoal e subjetiva de uso do advérbio, o locutor se propõe como sujeito do seu texto, construindo sentido(s) no texto. Vamos nos deter a essa classe gramatical, mesmo que, como já falamos, as marcas de subjetividade podem ser encontradas em diferentes classes gramaticais, apenas para exemplificar uma (entre as mais diversas) possibilidade de análise.

Iniciamos com o primeiro excerto, retirado do texto em anexo:

Um dia marcado pelo aumento elevado dos focos de incêndio na Amazônia, completa um ano nesta segunda-feira (10), com apenas 5\% dos responsáveis punidos, segundo a ONG Greenpeace.

\footnotetext{
3 Link da notícia: https://g1.globo.com/pa/para/noticia/2020/08/10/dia-do-fogo-completa-um-ano-com-apenas5percent-dos-responsaveis-punidos-aponta-greenpeace.ghtml. Acesso em: 2 ago. 2021.
} 


\section{PERcursos Linguísticos • Vitória (ES) •v. 11 •n. 29 • 2021 • ISSN: 2236-2592 • Dossiê temático $\bullet O$ texto na pesquisa e no ensino: conhecimentos, práticas e desafios na contemporaneidade •}

Destacamos a palavra apenas, que se caracteriza como um advérbio de exclusão. O sentido construído pelo uso desse termo enfatiza o dado que vem em seguida, os $5 \%$ dos responsáveis. Entende-se então que o uso do advérbio apenas significa que o número de responsáveis punidos é muito pequeno, diríamos insignificante, dada a importância do assunto. Seu uso nessa frase é acessório; se não tivéssemos esse termo, entenderíamos do mesmo jeito: “com 5\% dos responsáveis punidos". Portanto, mais uma vez, sua função principal é a de dar ênfase, ou seja, o locutor que o toma como possibilidade de marcar a ênfase acaba se colocando no texto à medida que aponta o olhar do interlocutor para essa informação.

Excerto 2:

"Mesmo com o Dia do Fogo sendo amplamente noticiado na imprensa do mundo inteiro, pouco foi feito para punir os culpados. Das 207 propriedades que registraram queima em floresta nesses dois dias, apenas 5,7\% foram autuadas", revela Rômulo Batista, porta-voz da campanha de Amazônia do Greenpeace Brasil.

Nesse parágrafo, queremos olhar para três termos: amplamente, pouco e apenas. Amplamente é um advérbio e indica que algo foi feito em grande quantidade, neste caso, seu sentido é de que a notícia foi bastante divulgada, ou seja, muitas pessoas ao redor do mundo a viram.

Em seguida, temos o uso advérbio de quantidade pouco, que serve como contraste do primeiro termo destacado, significa em pouca quantidade, em um número muito pequeno. Nesse caso, entendemos que muita coisa poderia e deveria ter sido feita contra esse crime ambiental, mas quase nada se concretizou, pouco foi feito. Portanto, o sentido construído e enfatizado por esses dois termos é dicotômico: mesmo com a grande divulgação do crime, quase nada foi feito para punição dos culpados.

Por fim, temos, novamente, o advérbio apenas, que constrói seu sentido, como no primeiro excerto, enfatizando o dado mostrado em seguida para dizer ao interlocutor que muitas outras propriedades poderiam e deveriam ter sido autuadas, mas somente em $5 \%$ delas aconteceu alguma ação, o que é um número muito pequeno. $\mathrm{O}$ uso desses advérbios, mobilizados pelo locutor do texto, apontam para o fato de direcionar a leitura do interlocutor para o que se comunica na notícia. O locutor propõe-se como sujeito quando mobiliza as formas da língua por sua conta. Instaura-se como "eu" à medida que se refere ao seu ato de discurso individual, em sua instância de discurso. Conforme Benveniste (2005, p. 288), "a realidade à qual ele remete é a realidade do discurso. É na instância de discurso na qual eu designa o locutor 


\section{PERcursos Linguísticos • Vitória (ES) •v. 11 •n. 29 • 2021 • ISSN: 2236-2592 • Dossiê temático $\bullet O$ texto na pesquisa e no ensino: conhecimentos, práticas e desafios na contemporaneidade •}

que este se enuncia como "sujeito"”. Eis aí uma possibilidade de identificarmos a subjetividade presente no texto em análise.

Excerto 3:

Pelo menos 66 deles já possuíam embargos por crimes ambientais anteriores ao Dia do Fogo, e reincidiram no delito.

Nesse trecho, gostaríamos de destacar a expressão pelo menos, que se classifica como uma locução adverbial. O termo possui um sentido de que do número total de proprietários (478), no mínimo, 66 já tinham praticado algum crime, o que é um número bem significativo. Essa informação também nos traz uma ideia de que uma pessoa que já cometeu alguma infração tem grandes chances de cometer de novo, pelo mesmo motivo, como é o caso desses 66 fazendeiros. Ao menos é o que podemos ler, a partir do sentido construído por essa locução empregada pelo locutor do texto.

\section{Excerto 4:}

No final do último mês de julho, uma equipe do Greenpeace sobrevoou a região afetada pelas queimadas do Dia do Fogo. As imagens feitas registram áreas já completamente desmatadas, outras ainda em fase de desmatamento e umas já convertidas em pasto, com atividade pecuária dentro.

Aqui, voltamos nosso olhar para o uso de dois termos: completamente e ainda. $\mathrm{O}$ primeiro é um advérbio usado para nos dizer o modo como as regiões ficaram depois do Dia do Fogo: completamente desmatadas. Ou seja, não foi uma parte da região, não foi $50 \%$, não foi quase toda destruída, ela foi desmatada completamente. $\mathrm{O}$ uso desse termo complementa o sentido e enfatiza a ação feita. Com esse advérbio, fica claro para o leitor que $100 \%$ do espaço foi desmatado.

A segunda forma linguística em negrito é o advérbio de tempo ainda, usado para dizer ao leitor que há outras áreas que não foram completamente desmatadas, como as primeiras, mas estas estão em fase de destruição, permanecem sendo desmatadas, ou seja, elas estão ainda em processo de desflorestação. Aqui temos uma marca que evidencia a temporalidade do dizer do locutor. Agora, "ainda" em fase de desmatamento. É a instância de discurso de quem fala. De quem usa a língua. De quem se propõe como sujeito do dizer. De quem se coloca no texto, ou seja, "a temporalidade humana com todo seu aparato linguístico revela a subjetividade inerente ao próprio exercício da linguagem". 


\title{
PERcursos Linguísticos • Vitória (ES) •v. 11 •n. 29 • 2021 • ISSN: 2236-2592 • Dossiê temático $\bullet O$ texto na pesquisa e no ensino: conhecimentos, práticas e desafios na contemporaneidade •
}

\section{Excerto 5:}

Somente os municípios de Novo Progresso, Itaituba, Altamira, São Félix do Xingu, Jacareacanga e Trairão foram responsáveis por $79 \%$ dos focos detectados no Pará em todo o mês de agosto. O recorde de queimadas foi sentido, inclusive, em São Paulo, quando o dia escureceu completamente às $15 \mathrm{hs}$, no dia 19 de agosto.

Sobre esse trecho, destacamos o uso de dois termos: somente e completamente. O primeiro se caracteriza como um advérbio de exclusão e funciona de maneira parecida com apenas. O sentido construído nesse uso é de que unicamente esses seis municípios citados foram os responsáveis por quase todos os focos em todo o estado. Sua função também é de enfatizar o dado mostrado em seguida, que já é, por si só, alarmante.

O segundo termo destacado, completamente, é um termo acessório para o entendimento da informação que o locutor quer passar, mas essencial para a construção do sentido da frase. Assim como seu uso no excerto 4, aqui também se destaca que o dia não ficou semi-iluminado ou com pouca luz, mas ficou totalmente escuro; um fato, com certeza, peculiar e raro de acontecer.

Percebemos que as marcas somente e completamente trazidas como exemplo são formas vazias, como defende Benveniste. Elas se preenchem de sentido nesse contexto e nessa instância de discurso, construída pelo locutor que se propõe como sujeito. Apoiamo-nos nas palavras de Benveniste (2005, p. 289):

\begin{abstract}
A linguagem é, pois, a possibilidade da subjetividade, pelo fato de conter sempre as formas linguísticas apropriadas à sua expressão; e o discurso provoca a emergência da subjetividade, pelo fato de consistir de instâncias discretas. A linguagem de algum modo propõe formas 'vazias' das quais cada locutor em exercício de discurso se apropria $[\ldots]$
\end{abstract}

\section{Excerto 6:}

Além disso, 580 focos de calor, o que representa 39,8\% do total, foram registrados em área de floresta e cerca de 32,8\% em áreas desmatadas.

Por fim, observamos o uso da expressão além disso, que é uma locução adverbial. Tratase de uma expressão usada para acrescentar algo ao que já foi dito. $\mathrm{O}$ texto evidencia diversas informações tristes e números preocupantes sobre o desmatamento, porém o locutor nos traz mais dados ainda. Este é o sentido da expressão: além de tudo o que já foi dito, ainda há mais dados e mais números assustadores. Essas informações são colocadas em cena pelo locutor que 


\section{PERcursos Linguísticos • Vitória (ES) •v. 11 •n. 29 • 2021 • ISSN: 2236-2592 • Dossiê temático $\bullet O$ texto na pesquisa e no ensino: conhecimentos, práticas e desafios na contemporaneidade •}

se propõe como sujeito de seu dizer, ou seja, a (sua) subjetividade é inerente ao próprio exercício da linguagem.

Todos os termos analisados servem para apoiar o sentido já trazido pelas outras informações das frases, mas sem esses termos, o leitor talvez não entenderia a gravidade da situação e não seria conduzido a chegar à conclusão, no final, de que o "Dia do fogo" trouxe desastres para o equilíbrio ambiental da região e causou fatos até irreversíveis. Isso construído e assumido pelo homem que fala, quando exercita a linguagem que lhe é própria, que é de sua natureza.

\section{Considerações finais}

Feito este estudo teórico com base nos pressupostos da teoria benvenistiana e analisando os advérbios de uma notícia, nossa conclusão parte de um pressuposto: não há texto neutro/imparcial e o sujeito que escreve sempre deixará suas marcas, de uma maneira ou de outra, através de pronomes, adjetivos, advérbios, ou seja, no arranjo que faz quando usa a língua.

Esperamos compartilhar este estudo com as demais áreas do conhecimento para que o mito do "texto neutro" seja desfeito e para que as pessoas entendam que não existe um texto totalmente e somente objetivo. Afinal, o modo como o falante usa a língua denuncia uma falta de objetividade, pois o locutor se apropria da língua para comunicar, e faz isso do seu jeito que é um jeito diferente do que qualquer outro sujeito faria. Nossa subjetividade está marcada nas nossas falas e escritas, pois nos apropriamos da língua e nos propomos como sujeitos quando a colocamos em uso.

Assim, destacamos que os sentidos são sempre únicos e irrepetíveis, a depender do modo como o sujeito imprime sua subjetividade quando toma a língua e a emprega de seu modo. Dessa forma, o sentido é dado pelo discurso, e não a priori. Os valores dos signos somente podem ser instituídos no instante em que o sujeito se apropria da língua em um ato enunciativo aqui e agora, sempre inéditos. Sublinhamos que os valores atribuídos aos advérbios selecionados para esta análise somente foram construídos nesta enunciação, pelo modo como eles se relacionam, por suas diferenças e por suas funções na constituição do próprio discurso. Isso evidencia que, para observar os sentidos de certas formas da língua, é preciso pensar no processo subjetivo inerente ao próprio uso da língua.

Sem dúvida, um maior número de análises, com maior aprofundamento teórico, possibilita chegar a evidências acerca da presença da subjetividade em textos que se querem 


\section{PERcursos Linguísticos • Vitória (ES) •v. 11 •n. 29 • 2021 • ISSN: 2236-2592 • Dossiê temático $\bullet O$ texto na pesquisa e no ensino: conhecimentos, práticas e desafios na contemporaneidade •}

objetivos. Fica aqui uma provisória tentativa de ver como o sentido se constrói no discurso, a partir da apropriação do sistema da língua por um locutor, ou melhor, por um homem que está na língua, a cada vez único e singular.

\section{Referências}

AZEVEDO, Gabriela. Dia do Fogo completa um ano com apenas 5\% dos responsáveis punidos, aponta Greenpeace. G1 Pará, Belém, 10 ago. 2020. Disponível em: https://g1.globo.com/pa/para/noticia/2020/08/10/dia-do-fogo-completa-um-ano-com-apenas5percent-dos-responsaveis-punidos-aponta-greenpeace.ghtml. Acesso em: 10 ago. 2021.

BENASSI, Maria Virginia Brevilheri. O gênero "notícia": uma proposta de análise e intervenção. In: CELLI - COLÓQUIO DE ESTUDOS LINGUÍSTICOS E LITERÁRIOS. 3, 2007, Maringá. Anais... Maringá, 2009, p. 1791-1799.

BENVENISTE, Émile. Problemas de linguística geral I. 5. ed. Campinas: Pontes, 2005.

BENVENISTE, Émile. Problemas de linguística geral II. 2. ed. Campinas: Pontes, 2006.

DIA DO FOGO COMPLETA UM ANO, COM LEGADO DE IMPUNIDADE. Greenpeace. Disponível em: https://www.greenpeace.org/brasil/florestas/dia-do-fogo-completa-um-anocom-legado-de-impunidade/. Acesso em: 2 ago. 2021.

FLORES, Valdir do Nascimento. Sujeito da enunciação: singularidade que advém da sintaxe da enunciação. D.E.L.T.A., v. 29, n. 1, p. 95-120. 2013. Disponível em: https://revistas.pucsp.br/index.php/delta/article/view/8623/14338. Acesso em: 2 ago. 2021.

GREENPEACE. Dia do fogo completa um ano, com legado de impunidade. 2020. Disponível em: https://www.greenpeace.org/brasil/florestas/dia-do-fogo-completa-um-ano-com-legadode-impunidade/. Acesso em: 2 ago. 2021.

LIMA, Rocha. Gramática normativa da língua portuguesa. 54. ed. Rio de Janeiro: José Olympio, 2018.

SAUSSURE, Ferdinand de. Curso de linguística geral. 28. ed. São Paulo: Cultrix, 2012. 


\section{PERcursos Linguísticos • Vitória (ES) •v. 11 •n. 29 • 2021 • ISSN: 2236-2592 • Dossiê \\ temático $\bullet O$ texto na pesquisa e no ensino: conhecimentos, práticas e desafios na contemporaneidade •}

\section{Anexo A}

\section{Dia do fogo completa um ano com apenas $5 \%$ dos responsáveis punidos, aponta Greenpeace}

ONG aponta que as ações do Dia do Fogo resultaram em 53 focos de calor dentro de Terras Indígenas e 534 em Unidades de Conservação

Por Gabriela Azevedo, G1 PA — Belém 10/08/2020 13h29 Atualizado há uma hora

Um dia marcado pelo aumento elevado dos focos de incêndio na Amazônia, completa um ano nesta segunda-feira (10), com apenas 5\% dos responsáveis punidos, segundo a ONG Greenpeace. O "Dia do Fogo" foi promovido por fazendeiros no Pará para gerar queimadas ilegais em diversos pontos da região, em agosto de 2019.

$\mathrm{Na}$ época, a mobilização foi denunciada por um jornalista de Novo Progresso, sudoeste do Estado. A Polícia Federal começou a investigar o caso após determinação do Ministério da Justiça e Segurança Pública. A investigação apontou que ação foi planejada em grupos de mensagens com fazendeiros, empresários e produtores rurais que teriam promovido as queimadas em áreas de unidades de conservação.

Em dois dias, o Instituto Nacional de Pesquisas Espaciais (INPE) detectou 1.457 focos de calor no estado, um aumento de $1.923 \%$ no mesmo período do ano anterior. O crescimento elevado também foi registrado de um dia para o outro. Enquanto no dia 9 de agosto, 101 focos foram detectados na região, no dia 10 o número pulou para 715, o que representa um aumento de $707 \%$ no número de queimadas.

"Mesmo com o Dia do Fogo sendo amplamente noticiado na imprensa do mundo inteiro, pouco foi feito para punir os culpados. Das 207 propriedades que registraram queima em floresta nesses dois dias, apenas 5,7\% foram autuadas", revela Rômulo Batista, porta-voz da campanha de Amazônia do Greenpeace Brasil.

De acordo com o Instituto Brasileiro do Meio Ambiente e dos Recursos Naturais Renováveis (Ibama), durante o último ano foram realizados 25 autos de infração devido a crimes ambientais na Amazônia. Esses autos foram traduzidos em R \$ 11 milhões em multas para os cofres da União.

\section{Propriedades identificadas}

O Greenpeace Brasil fez um levantamento com os Cadastros Ambientais Rurais (CAR) dos municípios de Novo Progresso, São Félix do Xingu Itaituba, Altamira, Jacareacanga e Trairão - atualizados pela última vez em fevereiro de 2020 - e identificou que quase metade dos focos de calor ocorridos no Dia do Fogo aconteceram dentro de propriedades rurais cadastradas no sistema fundiário do Pará. 


\section{PERcursos Linguísticos • Vitória (ES) •v. 11 •n. 29 • 2021 • ISSN: 2236-2592 • Dossiê \\ temático $\bullet O$ texto na pesquisa e no ensino: conhecimentos, práticas e desafios na contemporaneidade •}

A partir do cadastro, é possível identificar os proprietários dos 478 imóveis que tiveram focos de calor no dia da ação. As informações podem ser consultadas pelo sistema público da Secretaria de Estado de Meio Ambiente e Sustentabilidade do Pará (Semas/PA).

Pelo menos 66 deles já possuíam embargos por crimes ambientais anteriores ao Dia do Fogo, e reincidiram no delito. Destes imóveis, 99,37\% já apresentava traços de pastagem mapeados e classificados pelo MapBiomas em 2018.

\section{Áreas devastadas}

No final do último mês de julho, uma equipe do Greenpeace sobrevoou a região afetada pelas queimadas do Dia do Fogo. As imagens feitas registram áreas já completamente desmatadas, outras ainda em fase de desmatamento e umas já convertidas em pasto, com atividade pecuária dentro.

Em agosto de 2019 foi registrado o maior índice de focos de calor na Amazônia para o mês desde 2010. Somente os municípios de Novo Progresso, Itaituba, Altamira, São Félix do Xingu, Jacareacanga e Trairão foram responsáveis por $79 \%$ dos focos detectados no Pará em todo o mês de agosto. O recorde de queimadas foi sentido, inclusive, em São Paulo, quando o dia escureceu completamente às $15 \mathrm{hs}$, no dia 19 de agosto.

De acordo com o levantamento do Greenpeace, as ações do Dia do Fogo resultaram em 53 focos de calor dentro de Terras Indígenas e 534 em Unidades de Conservação. Além disso, 580 focos de calor, o que representa 39,8\% do total, foram registrados em área de floresta e cerca de $32,8 \%$ em áreas desmatadas. 